\title{
ANÁLISE DOS EFEITOS DA ICPC 01 (R1) - CONTRATOS DE CONCESSÃO NAS DECISÕES GERENCIAIS NAS EMPRESAS DE TRANSMISSÃO DE ENERGIA ELÉTRICA
}

\author{
Recebido em \\ Aprovado em \\ 09.12 .2017 \\ 18.12 .2017
}

\section{Maria Eveline Rodrigues Gomes}

Contadora, especialista em Gestão de Ativos do setor elétrico. Atuou na contabilidade patrimonial e gerencial de grandes empresas, como: Companhia Energética do Ceara-Coelce, Bandeirante Energia S/A e

Alupar S.A. Setor Elétrico. Nos últimos 10 anos, os trabalhos foram realizados na abordagem das novas Práticas Contábeis - IFRS, com ênfase na IFRIC-12(ICPC-01) e seus parâmetros sistêmicos (SAP). E-mail: maria.eveline@ig.com.br

\section{Henrique Formigoni}

Pós-Doutor pela Universidad de Salamanca, Espanha. Doutor em Ciências Contábeis pela FEA/USP e Mestre em Ciências Contábeis e Atuariais pela PUC/SP. Professor adjunto do Centro de Ciências Sociais e

Aplicadas da Universidade Presbiteriana Mackenzie e membro do núcleo docente permanente do Mestrado Profissional em Controladoria e Finanças Empresariais. Atuou na área contábil, em empresas de pequeno e médio porte, de diferentes setores (comerciais, industriais e de serviços), acumulando experiência na área de Administração, com ênfase em Ciências Contábeis, atuando principalmente nos temas sobre contabilidade societária e tributos. E-mail: hformigoni@mackenzie.br 


\section{RESUMO}

Este relato técnico tem por base a adoção pelas empresas de energia elétrica da ICPC 01 (R1) Contratos de Concessão, que trouxe alterações significativas nos registros contábeis relativos à receita e à infraestrutura do negócio para o setor, mais especificamente o de transmissão de energia. O objetivo deste relato foi analisar se houve alteração na fonte de informações utilizadas como base para tomada de decisões gerenciais pelos gestores das empresas de transmissão de energia elétrica após a adoção da ICPC 01 (R1). É um estudo exploratório, com abordagem qualitativa, realizado com cinco gestores da holding do Grupo Alupar Investimento S/A, utilizando-se um questionário com 12 perguntas abertas. Os resultados evidenciaram que as informações utilizadas para tomada de decisões internas provêm das normas regulatórias e que, praticamente, nenhuma decisão gerencial é tomada a partir das normas societárias. Concluiu-se, assim, que a ICPC 01 (R1) Contratos de Concessão não trouxe alterações na fonte de informações para a tomada de decisão pelos gestores das empresas de transmissão de energia elétrica do Brasil. Este relato contribui no sentido de destacar que as informações contábeis decorrentes da ICPC 01 (R1) não contribuem para o processo de gestão e tomada de decisão gerencial para as empresas da amostra.

\section{PALAVRAS-CHAVE}

Demonstrações regulatórias. Demonstrações societárias. Decisões gerenciais. Transmissão de energia elétrica. 


\section{QUESTÃO PRINCIPAL TRATADA NO TRABALHO}

Analisar se houve alteração na fonte de informações utilizadas como base para tomada de decisões gerenciais pelos gestores das empresas de transmissão de energia elétrica após a adoção da ICPC 01 (R1).

\section{RELATO DO CASO}

O setor de energia tem características próprias, pois produz uma mercadoria que não pode ser armazenada e tem que ser consumida no momento em que é gerada. Esse fato interliga, diretamente, a geração, a transmissão e a distribuição de energia elétrica, sendo fundamentais a eficiência e a confiabilidade na qualidade e na coordenação do sistema elétrico (ABREU, 2009).

A partir dos anos 1980 a energia passou a ser vista como um produto que poderia ser negociado no mercado, e para que se tornasse um negócio atraente, separaram-se os diversos setores do sistema de eletricidade - geração, transmissão, distribuição e comercialização. Para que essas empresas funcionassem de forma eficiente, foi necessário haver suas reestruturações (ABREU, 2009).
A publicação da Interpretação do Comitê de Pronunciamentos Contábeis ICPC 01 (R1) - Contratos de Concessão tem como escopo orientar a forma de aplicar as novas regras societárias (os pronunciamentos contábeis do $\mathrm{CPC}$ ) às concessionárias de serviços públicos, com relação aos bens, direitos e obrigações referentes a seus contratos de concessão. Com a publicação dessa Interpretação, deu-se início a discussões acerca da modelagem societária para as concessionárias de serviço público alcançados por ela, tendo como resultado a publicação da Orientação do Comitê de Pronunciamentos Contábeis OCPC 05 - Contratos de Concessão.

Essa OCPC basicamente define a quais tipos de concessão deve ser aplicada a ICPC 01 (R1) e qual modelo seguir: ativo financeiro, ativo intangível ou ambos, para os contratos de concessão de geração, transmissão e distribuição de energia, rodovias e ferrovias.

Com a divulgação da ICPC 01 (R1) e posteriormente da OCPC 05 , as mudanças na forma de contabilização, na apresentação dos ativos da concessão e nas demonstrações contábeis das empresas de energia elétrica geraram informações diferentes das normas e procedimentos estabelecidos pelo 
agente regulador do setor Elétrico, Agência Nacional de Energia Elétrica (Aneel).

Nesse contexto, o agente regulador, preocupado com a essência do serviço outorgado, resolveu instituir a contabilidade regulatória por meio da Resolução Normativa n. 396, de 23 de fevereiro de 2010, por entender que a aplicação das normas societárias impossibilita uma divulgação adequada das informações contábeis dos ativos vinculados à concessão.

As novas regras impostas estabeleceram a necessidade de demonstrações contábeis próprias, considerando-se as imposições legais contidas na Resolução 396/2010. Dessa forma, as empresas de energia elétrica, a partir de 31.12.2011, ficaram obrigadas a disponibilizar suas informações contábeis dentro do escopo das legislações societária e regulatória.

As mudanças contábeis estabeleceram nova estrutura de registro contábil para os ativos imobilizados, que para a concessão do serviço público de transmissão é o foco principal do retorno do investimento. Dessa forma, questiona-se qual fonte de informação disponível o gestor da empresa de transmissão de energia elétrica, para tomada de decisões gerenciais, levará em conta: societária ou regulatória?
O objetivo deste relato é analisar se houve alteração na fonte de informações utilizada como base para tomada de decisões gerenciais pelos gestores das empresas de transmissão de energia elétrica após a adoção da ICPC 01 (R1).

A principal justificativa para a realização deste estudo vem da observação prática da autora que verificou que o diretor financeiro da empresa pesquisada solicitava apenas balancetes regulatórios e não utilizava informações societárias ajustadas à norma ICPC 01 .

Assim, este relato contribui para o esclarecimento sobre a utilidade da norma societária ICPC 01 - Contratos de Concessão para os gestores das empresas de transmissão de energia elétrica no Brasil.

\section{EMBASAMENTO TEÓRICO- -EMPÍRICO}

\section{Transmissão de energia}

O sistema de transmissão é responsável pelo transporte de energia a partir dos centros de produção até os centros de consumo. A eletricidade geralmente é transmitida a longas distâncias através de linhas aéreas de transmissão, que compreendem 
toda a rede que interliga as geradoras às subestações de distribuição.

A expansão do sistema de transmissão de energia elétrica do Brasil ocorreu de forma semelhante à expansão da geração de energia, por meio dos leilões públicos realizados pela Aneel, nos quais os vencedores são elegíveis pelo critério do menor valor da receita e, no caso da transmissão, pela menor Receita Anual Permitida (RAP). O objetivo do marco regulatório foi atingido, pois os leilões atraíram o investidor privado e o público, e os deságios ofertados pelos participantes foram cada vez maiores, fazendo que os lucros desse segmento sejam minimizados, garantindo a modicidade tarifária, que tem como objetivo proporcionar menores tarifas para o consumidor.

Os projetos para linhas de transmissão se caracterizam pelos reduzidos riscos operacionais e de implantação. Geralmente, a engenharia utilizada na construção é simples e a tecnologia dos equipamentos utilizados é internacionalmente conhecida. É importante ressaltar que os riscos ambientais nesse segmento elétrico são mínimos, se comparados aos riscos do segmento da geração de energia. Essas características peculiares ao negócio da transmissão foram institucionalmente desenvolvidas para garantir a atratividade aos investidores.

A RAP é a remuneração que as transmissoras recebem para disponibilizar o transporte de energia ao operador nacional do sistema elétrico e prestar o serviço público de transmissão aos usuários acessantes.

De acordo com a Resolução Normativa n. 230/2006, o reajuste da RAP é realizado considerando-se:

1. Para as transmissoras que celebraram contrato de concessão até 2006, a RAP é atualizada com base no índice geral de preços do mercado (IGP-M) da Fundação Getulio Vargas (FGV).

2. Para as transmissoras que celebraram contrato de concessão assinados a partir de 2006, a RAP é atualizada com base no Índice de Preços ao Consumidor Amplo (IPCA) do Instituto Brasileiro de Geografia e Estatística (IBGE).

\section{Adoção da ICPC 01 nas empresas de transmissão de energia elétrica}

As empresas de transmissão de energia elétrica estão subordinadas às regras do poder concedente e recebem delegação para a 
prestação do serviço público de transmissão de energia, iniciada a partir da assinatura do contrato de concessão. As normas para outorga e prorrogação das concessões dos serviços públicos estão normatizadas pela Lei n. 8.987, de 13.2.1995, complementada pela Lei n. 9.047, de 7.7.1995, que tratou diretamente de assuntos específicos para o setor elétrico. As empresas de transmissão, por serem concessionárias de serviço público, têm a obrigatoriedade, para fins societários, de acatar os pronunciamentos emitidos pelo Comitê de Pronunciamentos Contábeis (CPC) adotados pela Aneel e, para fins regulatórios, devem atender às determinações legais do agente regulador - Aneel.

A ICPC 01 (correlata à IFRIC 12) estabelece o entendimento para a atividade de transmissão de energia, classificando o ativo financeiro como Empréstimo e Recebíveis. Como composição dos custos, têm-se (i) a capitalização do custo de empréstimo, que não deve ser considerada no imobilizado; (ii) a variação na taxa efetiva, que deverá ser ajustada diretamente no resultado no momento em que for apurada a diferença entre o realizado e o orçado. O reajuste da RAP deve ser mensal.
Em virtude das discussões dos agentes reguladores e dos concessionários sobre a ICPC 01 (R1), o CPC editou a Orientação Técnica - OCPC 05, com a finalidade de esclarecer dúvidas quanto à adoção da ICPC 01(R1) pelas empresas reguladas brasileiras.

A atividade de transmissão, que é o foco deste relato, apresenta as seguintes características em seus contratos de concessão:

A. As empresas de transmissão têm a obrigação contratual de construir, operar e manter a infraestrutura. A obrigação da construção da infraestrutura pode estar caracterizada de forma implícita ou explícita no contrato de concessão.

B. A maioria dos contratos tem o prazo de concessão por 30 anos.

c. Na média, a vida útil econômica estimada do conjunto dos bens integrantes da infraestrutura é superior ao prazo de concessão.

D. A atividade de transmissão não é competitiva. Não existe competição entre empresas (existe entre os investidores, para obtenção da concessão).

E. A concessionária (empresa transmissora/operadora) é interposta entre o poder concedente e os usuários. 
F. A atividade é sujeita à condição de generalidade (direito de livre acesso) e de continuidade.

G. Alguns contratos têm garantia de manutenção do equilíbrio econômico-financeiro.

H. O contrato estabelece quais os serviços e para quem (usuários) o serviço deve ser prestado.

I. O preço é regulado (tarifa) e denominado Receita Anual Permitida (RAP). A transmissora não deve negociar preços com usuários. Geralmente, a RAP está sujeita à revisão anual devido ao aumento de ativos e de despesas operacionais decorrentes de modificações, reforços e ampliações de instalações.

J. Os bens são reversíveis ao poder concedente no final da concessão, com direito de recebimento de indenização (caixa) do poder concedente sobre os investimentos ainda não amortizados.

к. As linhas de transmissão são de uso dos geradores, das distribuidoras, dos consumidores livres, exportadores e importadores.

O entendimento do mercado e dos reguladores é que a atividade de transmissão no Brasil foi planejada para ser adimplen- te, garantir a saúde financeira e evitar risco de crédito do sistema de transmissão.

De acordo com a OCPC 05, o modelo de contabilização para a infraestrutura a ser usado pelas concessionárias de transmissão de energia é o Modelo Ativo Financeiro e deve seguir estas orientações:

A. Aplicação retroativa de todos os contratos de concessão assinados após 1995 (novas licitações) para evitar distorções na apuração da taxa efetiva de juros do ativo financeiro relacionado à construção.

B. Critério para a separação (alocação) da receita de construção, operação e manutenção do total do contrato.

c. Aplicação do índice de inflação do contrato para calcular corretamente a inflação já incorrida do valor total do contrato e respectiva alocação entre receita de construção, operação e manutenção.

D. Apuração da remuneração incorrida da parcela do ativo financeiro da construção, da operação e da manutenção separadamente.

E. Critério de separação do valor do faturamento mensal (fluxo de caixa) para alocação da parcela de receita de 
operação e manutenção e da parcela a ser reduzida do saldo do ativo financeiro, considerada como amortização do contrato (recebimento).

F. Critério de apuração da margem de construção.

G. Critério para apuração da taxa efetiva de juros.

\section{Modelo ativo financeiro}

No modelo ativo financeiro os ativos da concessão, bens reversíveis, que são os ativos imobilizados, não são reconhecidos nem registrados na contabilidade societária, pois entende-se que o concessionário apenas presta um serviço e, por esse motivo, reconhece como ativo financeiro amortizável os valores recebíveis pela prestação desse serviço público de energia.

Devido à garantia de recebimento da RAP, que contempla a construção, a operação e a manutenção que é recebida pela disponibilidade do transporte de energia e não pela utilização da infraestrutura por parte dos geradores, distribuidores, exportadores, importadores e consumidores livres, os concessionários possuem o direito incondicional adquirido contratualmente do recebimento desse ativo financeiro, que é reconhecido como valores recebíveis pelo valor do serviço.

O ICPC 01 (R1) modificou o tratamento econômico e contábil para os ativos imobilizados da concessão. Para Iudícibus et al. (2010, p. 147), o modelo proposto pela ICPC 01 (R1) alterou substancialmente a maneira como determinados tipos de concessão são contabilizados no cenário nacional, haja vista que o foco passa a ser a essência econômica da transação e não a forma. Pode-se dizer que se trata de um modelo contábil mais adequado à medida que reflete os modelos econômicos que são específicos a tais tipos de contratos.

$\mathrm{O}$ ativo financeiro é classificado como um instrumento financeiro recebível, sendo inicialmente mensurado pelo seu valor justo. Posteriormente, esse recebível (Caixa) é mensurável pelo valor amortizável, que é a RAP regulatória, ou seja, pelo valor inicial reconhecido menos os recebimentos da RAP mais os juros (WACC - utilizados para o setor de energia como base para cálculos do modelo do negócio) sobre o valor amortizável e o método usado para este cálculo é o da taxa efetiva de juros.

O Pronunciamento Técnico CPC 38 - Instrumentos Financeiros: Reconhecimento e Mensuração define a taxa efetiva 
de juros como "a taxa de desconto que, aplicada sobre os pagamentos ou recebimentos futuros estimados ao longo da expectativa de vigência do instrumento financeiro resulta no valor contábil líquido do ativo ou passivo financeiro" (IUDÍCIBUS et al., 2010, p. 462).

Com base na estrutura do modelo de ativo financeiro, é possível calcular o valor do ativo financeiro (recebível) a cada ano da concessão. A Tabela 1 demonstra o resultado da modelagem do ativo financeiro para fins de contabilização societária. No exemplo usado, o valor de $\mathrm{R} \$ 80.458$ representa o investimento total na construção da infraestrutura - ativos da concessão até
31.12.2011; a receita de construção de R\$ 1.904 é a nova adição no período em construção da infraestrutura; a recuperação do ativo financeiro refere-se à RAP recebida para os dois meses de operação da transmissora (exemplo usado); o resultado da operação refere-se ao percentual usado para a margem da atividade de transmissão na modelagem, ou seja, quanto de margem operacional é preciso para cobrir os custos. O total de receita financeira ( $R \$ 2.792)$ é a TIR do negócio, ou seja, o retorno do investimento com a utilização de uma taxa de $3,5 \%$, que, no modelo, refere-se à taxa que o investidor usou como retorno do investimento para entrar no leilão.

TABELA 1 - Modelagem do Ativo Financeiro (R\$/Mil) - Transmissoras Alupar

\begin{tabular}{ll}
\hline Ativo Financeiro-Data Base & $\mathbf{3 1 . 1 2 . 2 0 1 1}$ \\
\hline Ativo Financeiro Inicial & 80.458 \\
\hline Receita da Construção & 1.904 \\
\hline Recuperação do Ativo Financeiro & -482 \\
\hline Resultado da Operação & 65 \\
\hline Receita Financeira & 2.792 \\
\hline Ativo Financeiro Final & 84.737 \\
\hline Taxa de Aplicação & $3,50 \%$ \\
\hline AF CIRCULANTE & 10.497 \\
\hline AF NÃO CIRCULANTE & 74.240 \\
\hline
\end{tabular}

Fonte: Elaborada pelos autores. 
Para fins de registro, o CPC 38 - Instrumentos Financeiros estabelece que um ativo financeiro deve ser classificado como:

A. empréstimo ou recebível;

B. ativo financeiro disponível para venda;

c. ativo financeiro mensurado ao valor justo por meio do resultado.

No caso de a contabilização do ativo financeiro ser registrada como empréstimo ou recebível ou ativo financeiro mensurado ao valor justo por meio do resultado, o CPC 38 obriga que a parcela referente aos juros calculados com base no método da taxa efetiva de juros seja reconhecida no resultado e que a contabilização dos juros deve impactar imediatamente o resultado do período.

A contabilização do ativo financeiro das transmissoras de energia elétrica, para fins societários, está concentrada no Ativo Circulante e Realizável a Longo Prazo, enquanto na contabilidade regulatória esse registro se concentra no Imobilizado e Intangível. Os impactos no registro contábil dessa divergência na contabilização estão especificados no Quadro 1.

\begin{tabular}{|c|c|c|c|}
\hline Regulamentação & Descrição & $\begin{array}{l}\text { Contabilidade } \\
\text { Societária }\end{array}$ & $\begin{array}{l}\text { Contabilidade } \\
\text { Regulatória }\end{array}$ \\
\hline ICPC 01 & $\begin{array}{l}\text { Ativo financeiro da } \\
\text { concessão }\end{array}$ & $\begin{array}{l}\text { Reconhece para fins } \\
\text { societários todo o custo } \\
\text { para construir a } \\
\text { estrutura física da } \\
\text { Transmissão-Obras de } \\
\text { Infraestrutura }\end{array}$ & $\begin{array}{l}\text { Não reconhece, pois o } \\
\text { custo da infraestrutura } \\
\text { está demonstrado nos } \\
\text { ativos imobilizados da } \\
\text { concessão }\end{array}$ \\
\hline ICPC 01 & $\begin{array}{l}\text { Receita da concessão de } \\
\text { transmissão }\end{array}$ & $\begin{array}{l}\text { Resultado Operacional } \\
\text { da Transmissão para } \\
\text { fins societários, durante } \\
\text { o prazo de concessão }\end{array}$ & $\begin{array}{l}\text { A receita do negócio } \\
\text { Transmissão para fins } \\
\text { regulatórios é } \\
\text { reconhecida como } \\
\text { Receita da Transmissão } \\
\text { da Rede Básica }\end{array}$ \\
\hline
\end{tabular}

QUADRO 1 - Legislações regulatória e societária e seus impactos na contabilidade

Fonte: Elaborado pelos autores.

continua 


\begin{tabular}{|c|c|c|c|}
\hline Regulamentação & Descrição & $\begin{array}{l}\text { Contabilidade } \\
\text { Societária }\end{array}$ & $\begin{array}{l}\text { Contabilidade } \\
\text { Regulatória }\end{array}$ \\
\hline ICPC 01 & $\begin{array}{l}\text { Receita de remuneração } \\
\text { dos ativos da concessão }\end{array}$ & $\begin{array}{l}\text { Resultado Operacional } \\
\text { da Transmissão para } \\
\text { fins societários, durante } \\
\text { o prazo de concessão }\end{array}$ & $\begin{array}{l}\text { A remuneração é } \\
\text { reconhecida anualmente } \\
\text { na publicação da } \\
\text { Resolução } \\
\text { Homologatória da RAP, } \\
\text { conforme termos do } \\
\text { contrato de concessão }\end{array}$ \\
\hline $\begin{array}{l}\text { Aneel-Resolução } \\
474 / 2012\end{array}$ & $\begin{array}{l}\text { (-) Depreciação } \\
\text { acumulada }\end{array}$ & $\begin{array}{l}\text { Não há depreciação, } \\
\text { pois não há Ativos } \\
\text { Imobilizados }\end{array}$ & $\begin{array}{l}\text { Calculados com base na } \\
\text { Resolução } 474 \text { de } \\
\text { 12/02/2012, para fins } \\
\text { regulatórios }\end{array}$ \\
\hline CPC 32 & $\begin{array}{l}\text { IR/CSLL Diferidos } \\
\text {-Receita Remuneração }\end{array}$ & $\begin{array}{l}\text { Calculado sobre a } \\
\text { remuneração da } \\
\text { concessão }\end{array}$ & Não aplicável \\
\hline СРС 32 & $\begin{array}{l}\text { IR/CSLL diferidos } \\
\text {-Receita Remuneração }\end{array}$ & $\begin{array}{l}\text { Calculado sobre a } \\
\text { remuneração da } \\
\text { concessão }\end{array}$ & Não aplicável \\
\hline
\end{tabular}

Não fazem parte do Investimento, é criada uma margem de

CPC 20

Custos de Empréstimos

construção para a receita de construção

(Receita de

Remuneração)

\begin{tabular}{llll}
\hline CPC 38 & $\begin{array}{l}\text { Instrumentos } \\
\text { Financeiros }\end{array}$ & $\begin{array}{l}\text { Aplicado no cálculo do } \\
\text { ativo financeiro }\end{array}$ & Não aplicável \\
\hline CPC 17 & Receita de Construção & Resultado Operacional & $\begin{array}{l}\text { Investimento - } \\
\text { Imobilizado em Curso }\end{array}$ \\
\hline CPC 17 & Custo de Construção & Despesa Operacional & $\begin{array}{l}\text { Investimento - } \\
\text { Imobilizado em Curso }\end{array}$ \\
\hline CPC 27 & Imobilizado & Não aplicável & $\begin{array}{l}\text { Ativos da Concessão, } \\
\text { contabilizados no Grupo } \\
\text { Imobilizado }\end{array}$ \\
\hline
\end{tabular}

São considerados Custos do Investimento quando os ativos estão na fase de construção

QUADRO 1 - Legislações regulatória e societária e seus impactos na contabilidade

Fonte: Elaborado pelos autores.

continua 
ANÁLISE DOS EFEITOS DA ICPC 01 (R1) - CONTRATOS DE CONCESSÃO NAS DECISÕES GERENCIAIS NAS EMPRESAS DE TRANSMISSÃO DE ENERGIA ELÉTRICA

\begin{tabular}{llll}
\hline Regulamentação & Descrição & $\begin{array}{l}\text { Contabilidade } \\
\text { Societária }\end{array}$ & $\begin{array}{l}\text { Contabilidade } \\
\text { Regulatória }\end{array}$ \\
\hline \multirow{2}{*}{$\begin{array}{l}\text { Receita Regulatória- } \\
\text { RAP }\end{array}$} & $\begin{array}{l}\text { Receita da Transmissão- } \\
\text { Rede Básica }\end{array}$ & $\begin{array}{l}\text { Amortização (Recebível/ } \\
\text { Caixa) do Ativo }\end{array}$ & $\begin{array}{l}\text { Receita Anual Permitida } \\
\end{array}$ \\
& Financeiro ao longo da & - Receita da Rede Básica \\
& concessão & \\
\hline
\end{tabular}

QUADRO 1 - Legislações regulatória e societária e seus impactos na contabilidade Fonte: Elaborado pelos autores.

O ativo financeiro é o valor recebível para a atividade de transmissão, e tem a sua amortização ao longo da concessão. A amortização do ativo financeiro da atividade de transmissão de energia é a recuperação financeira, que se dá por meio do faturamento mensal da Receita Anual Permitida durante o prazo de concessão. Para fins societários, a Receita da Rede Básica - Transmissão é considerada amortização do Ativo Financeiro, constituído durante o período de construção da linha.

\section{Contabilidade regulatória -} Setor Elétrico

Ferreira (2009) observa que a contabilidade regulatória foi criada para um fim específico, tendo um objetivo convergente com a contabilidade societária. No entanto, aprofunda-se na busca da correta demonstração da situação econômica e patrimonial da atividade concedida, servindo ainda como instrumento de controle e monitoramento dessa atividade. As empresas de energia, dentre elas as transmissoras, devem seguir os padrões e as regras contábeis normatizadas pela Aneel e, assim, estão obrigadas às determinações do plano de contas contido no Manual de Contabilidade do Setor Elétrico, estabelecido pela Resolução Normativa n. 444/2001.

Os investimentos da atividade de transmissão de energia estão concentrados nos ativos imobilizados regulatórios. Isso explica a preocupação da Aneel em estabelecer suas próprias regras regulatórias, pois, nos padrões normativos societários, o grupo de imobilizado não mais existe.

O Departamento Nacional de Água e Energia Elétrica (Dnaee) publicou, em 1994, a Portaria n. 815, de 30.11.1994, que obriga os concessionários do serviço pú- 
blico de energia elétrica a manter atualizado e organizado o cadastro de propriedade em função do serviço concedido, conforme as "instruções para contabilização e controle do ativo imobilizado". Para dar continuidade ao processo de melhoria dos controles de ativos, a Aneel publicou a Resolução n. 367, em junho de 2009, que foi um marco no setor, por possibilitar ao agente regulador a uniformização dos controles de ativos com o objetivo de facilitar a fiscalização e a análise.

Os ativos do setor elétrico devem ser contabilizados, inicialmente, no grupo de Ativo Imobilizado em Curso e, após a conclusão da obra, todos os equipamentos, os serviços e os custos indiretos e diretos são transferidos para Imobilizados em Serviço, consolidados em grupos de ativos chamados UAR (Unidade de Adição e Retirada) e, a partir da Unitização, que é a entrada da operação contábil regulatória, dar-se-á início ao processo de amortização/depreciação.

Fica bastante claro o controle exercido sobre o patrimônio, especificamente sobre o ativo da concessão usado na prestação do serviço concedido, seja na adição, seja na desativação de bens, seja na aplicação dos critérios estabelecidos para depreciação.

As diferenças encontradas entre os modelos Societário e Regulatório trazem mudanças significativas para a forma de apresentação desses dados nos demonstrativos contábeis, conforme mostra o Quadro 2.

\begin{tabular}{|c|c|c|}
\hline ITEM & Modelo Societário Vigente & Modelo Regulatório Vigente \\
\hline $\begin{array}{l}\text { Evidenciação do Ativo } \\
\text { Adquirido }\end{array}$ & $\begin{array}{l}\text { Representação por meio da conta } \\
\text { Ativo financeiro (Ativo Circulante/ } \\
\text { Não Circulante) }\end{array}$ & $\begin{array}{l}\text { Representação por meio do grupo } \\
\text { ativo imobilizado (bens físicos) }\end{array}$ \\
\hline Evolução do ativo & $\begin{array}{l}\text { Amortização com base na RAP } \\
\text { recebida (homologada anualmente } \\
\text { pela Aneel) }\end{array}$ & $\begin{array}{l}\text { Depreciação com base na vida útil } \\
\text { do bem (Res. 474/2012) }\end{array}$ \\
\hline Investimentos Realizados & $\begin{array}{l}\text { São acrescidos no grupo ativo } \\
\text { financeiro e amortizados pelo prazo } \\
\text { de vigência do contrato, logo que } \\
\text { homologado na RAP. }\end{array}$ & $\begin{array}{l}\text { São acrescidos ao grupo ativo } \\
\text { imobilizado e depreciados a taxas } \\
\text { de depreciação que consideram a } \\
\text { vida útil do bem. }\end{array}$ \\
\hline
\end{tabular}

QUADRO 2 - Diferenças dos modelos societário e regulatório Fonte: Elaborado pelos autores. 


\section{METODOLOGIA}

Este relato, quanto aos objetivos, caracteriza-se como sendo do tipo exploratório; quanto à abordagem do problema, trata-se de uma pesquisa qualitativa, e em relação aos procedimentos para a coleta dos dados, caracteriza-se como uma survey.

A pesquisa foi realizada por meio de um questionário com 12 perguntas abertas, enviados a dez gestores (diretores, controllers, contadores) da holding Alupar, de forma a se buscar avaliar quais informações eles estão considerando nas decisões gerenciais após a adoção da ICPC 01 (R1); as relativas às normas societárias e/ou regulatórias. No entanto, três deles não foram respondidos e dois foram desconsiderados pela falta de aderência das respostas ao tema da pesquisa. Dessa forma, cinco questionários compuseram a amostra final e foram analisados, o que corresponde a um terço do total das empresas de transmissão de energia consideradas no estudo. A análise dos dados primários foi realizada por meio da interpretação das respostas dos cinco questionários (BEUREN, 2008).

A pesquisa foi desenvolvida nas empresas de transmissão de energia elétrica do Grupo Alupar Investimento S/A, composto por 20 transmissoras que estão nas fases operacional e pré-operacional. Como amostra foram consideradas apenas as transmissoras que estão na fase operacional, totalizando 15 empresas que fazem parte do Grupo Alupar, holding que centraliza todas as decisões operacionais e estratégicas.

A Alupar Investimento S/A é uma sociedade de capital aberto, que tem como objeto principal a participação em outras sociedades atuantes no setor de energia elétrica no Brasil e na América Latina. Tem participação em 19 empresas de transmissão de energia elétrica no Brasil, com aproximadamente $5.465 \mathrm{~km}$ de linhas - 4.750 $\mathrm{km}$ estão em operação e $715 \mathrm{~km}$ em fase pré-operacional, com voltagens entre 230 Kv e $525 \mathrm{Kv}$. O prazo de concessão é de 30 anos para todas as instalações de transmissão que estão localizadas nas regiões Norte e Nordeste do país, nos estados do Pará, Maranhão, Piauí e Ceará; na região Sul, no estado de Santa Catarina; na região Sudeste, nos estados de Minas Gerais e Espírito Santo; no Centro-Oeste, no estado de Mato Grosso; e em futuro próximo, nos estados do Amazonas e de Roraima.

Os investimentos em transmissão no $1^{\circ}$ semestre de 2012 somaram o montante de R\$ 68,1 milhões. A participação da Alupar 
em todas as empresas de transmissão tem um percentual acima de 50\%. A Figura 1 apresenta a estrutura societária com todas as empresas em que o Grupo Alupar Investimento S/A tem participação acionária. Contém as 20 empresas de Transmissão do Grupo Alupar com o período de concessão e a RAP para o ciclo 2012-2013, considerados na Resolução Homologatória Aneel 1.313, de 26 de junho de 2012. As transmissoras TNE e ETSE não estão consideradas nessa resolução devido ao fato de que a entrada em operação dessas empresas não está pre- vista para esse ciclo, portanto seus valores de RAP foram considerados conforme estabelecido nos Contratos de Concessão.

A Alupar exerce administração direta nas transmissoras ETVG, ETEM, TME, ETES, TNE e STN; nas Transmineiras, exerce o controle por meio da holding Transminas S/A; por meio da holding TBE, exerce o controle na ECTE, ETEP, ETSE, ESDE, ERTE, EATE, ENTE, Lumitrans, STC e EBTE. Na Tabela 2 estão todas as empresas transmissoras do Grupo Alupar S/A.

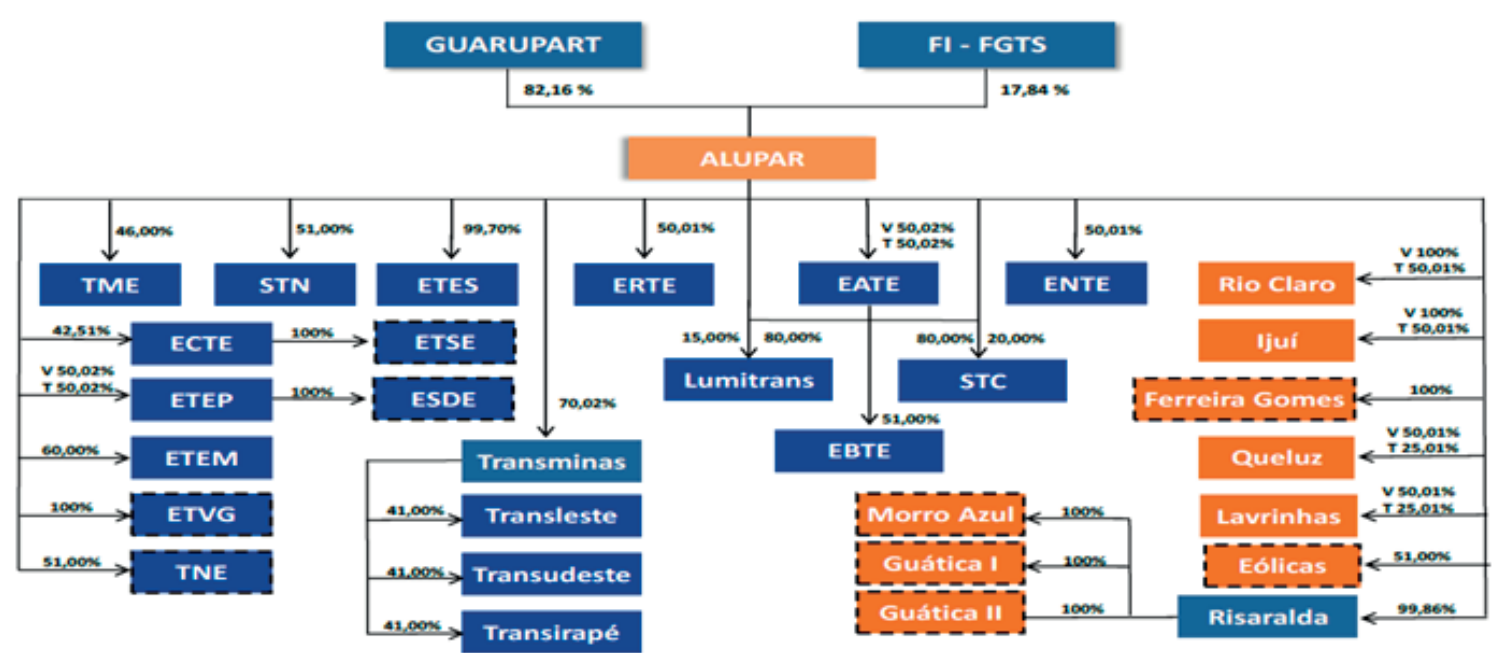

FIgURA 1 - Estrutura societária da Alupar Investimento S/A

Fonte: Alupar (2012). 
TABELA 2 - Empresas Transmissoras do Grupo Alupar Investimento S/A

\begin{tabular}{|c|c|c|c|c|}
\hline DESCRIÇÃO & EXTENSÃO & Condições Operacionais & Período Concessão & $\begin{array}{l}\text { RAP-Ciclo } \\
\text { 2012-2013 }\end{array}$ \\
\hline $\begin{array}{l}\text { Empresa Paraense de } \\
\text { Transmissão de Energia } \\
\text { S/A-Etep }\end{array}$ & $323,0 \mathrm{~km}$ & Operacional & Jun. 2001 a jun. 2031 & 72.847 \\
\hline $\begin{array}{l}\text { Empresa Norte de } \\
\text { Transmissão de Energia } \\
\text { S/A-Ente }\end{array}$ & $464,0 \mathrm{~km}$ & Operacional & Dez. 2002 a dez. 2032 & 167.314 \\
\hline $\begin{array}{l}\text { Empresa Regional de } \\
\text { Transmissão de Energia } \\
\text { S/A-Erte }\end{array}$ & $179,0 \mathrm{~km}$ & Operacional & Dez. 2002 a dez. 2032 & 29.568 \\
\hline $\begin{array}{l}\text { Empresa Amazonense de } \\
\text { Transmissão de Energia } \\
\text { S/A-Eate }\end{array}$ & $924,0 \mathrm{~km}$ & Operacional & Jun. 2001 a jun. 2031 & 319.748 \\
\hline $\begin{array}{l}\text { Empresa Catarinense de } \\
\text { Transmissão de Energia } \\
\text { S/A-ECTE }\end{array}$ & $252,5 \mathrm{~km}$ & Operacional & Nov. 2000 a nov. 2030 & 70.610 \\
\hline $\begin{array}{l}\text { Sistema de Transmissão } \\
\text { Nordeste S/A-STN }\end{array}$ & $541,0 \mathrm{~km}$ & Operacional & Fev. 2004 a fev. 2034 & 133.871 \\
\hline $\begin{array}{l}\text { Companhia Transleste de } \\
\text { Transmissão-Transleste }\end{array}$ & $150,0 \mathrm{~km}$ & Operacional & Fev. 2004 a fev. 2034 & 30.326 \\
\hline $\begin{array}{l}\text { Companhia Transudeste de } \\
\text { Transmissão-Transudeste }\end{array}$ & $140,0 \mathrm{~km}$ & Operacional & Mar. 2005 a mar. 2035 & 18.797 \\
\hline $\begin{array}{l}\text { Companhia Transirapé de } \\
\text { Transmissão-Trasirapé }\end{array}$ & $65,0 \mathrm{~km}$ & Operacional & Mar. 2005 a mar. 2035 & 16.767 \\
\hline $\begin{array}{l}\text { Sistema de Transmissão } \\
\text { Catarinense S/A-STC }\end{array}$ & $195,0 \mathrm{~km}$ & Operacional & Abr. 2006 a abr. 2037 & 30.056 \\
\hline $\begin{array}{l}\text { Lumitrans Companhia } \\
\text { Transmissora de Energia } \\
\text { Elétrica-Lumitrans }\end{array}$ & $51,0 \mathrm{~km}$ & Operacional & Fev. 2004 a fev. 2034 & 19.783 \\
\hline $\begin{array}{l}\text { Empresa de Transmissão do } \\
\text { Espírito Santo S.A.-Etes }\end{array}$ & $107,0 \mathrm{~km}$ & Operacional & Abr. 2007 a abr. 2037 & 11.132 \\
\hline $\begin{array}{l}\text { Transchile Charrúa de } \\
\text { Transmisíon -Transchile }\end{array}$ & $200,0 \mathrm{~km}$ & Operacional & Chile & - \\
\hline
\end{tabular}


TABELA 2 - Empresas Transmissoras do Grupo Alupar Investimento S/A

\begin{tabular}{lllll}
\hline DESCRIÇÃO & EXTENSÃO & Condições Operacionais & Período Concessão & $\begin{array}{l}\text { RAP-Ciclo } \\
\text { 2012-2013 }\end{array}$ \\
\hline $\begin{array}{l}\text { Empresa Brasileira de } \\
\begin{array}{l}\text { Transmissão de Energia } \\
\text { S.A.-EBTE }\end{array}\end{array}$ & $775,0 \mathrm{~km}$ & Operacional & Out. 2008 a out. 2038 & 33.500 \\
\hline $\begin{array}{l}\text { Transmissora Matogrossense } \\
\text { de Energia S.A.-TME }\end{array}$ & $348,0 \mathrm{~km}$ & Operacional & Nov. 2009 a nov. 2039 & 33.388 \\
\hline $\begin{array}{l}\text { Empresa Santos Dumont de } \\
\text { Energia S.A.-Esde }\end{array}$ & $3 \mathrm{~km}$ & Pré-Operacional & Nov. 2009 a nov. 2039 & 10.098 \\
$\begin{array}{l}\text { Transmissão de Energia do } \\
\text { Mato Grosso S.A.-Etem }\end{array}$ & $235,0 \mathrm{~km}$ & Operacional & Jul. 2010 a jul. 2040 & 10.046 \\
\hline $\begin{array}{l}\text { Empresa de Transmissão de } \\
\text { Várzea Grande S.A.-ETVG }\end{array}$ & $850 \mathrm{~m}$ & Pré-Operacional & Dez. 2010 a dez. 2040 & 3.398 \\
\hline $\begin{array}{l}\text { Transnorte - Transnorte } \\
\text { Energia S.A-TNE }\end{array}$ & $715 \mathrm{~km}$ & Pré-Operacional & Jan. 2012 a jan. 2042 & 121.128 \\
\hline $\begin{array}{l}\text { Empresa de Transmissão } \\
\text { Serrana S.A.-Etse }\end{array}$ & $0 \mathrm{~km}$ & Pré-Operacional & Mai. 2012 a mai. 2042 & 14.423 \\
\hline
\end{tabular}

Fonte: Alupar (2012).

\section{APRESENTAÇÃO DOS RESULTADOS}

\section{Descrição das análises - aderência dos contratos de concessão}

Inicialmente, foi realizada a análise dos contratos de concessão com o intuito de constatar se as transmissoras atendem às especificações da ICPC 01 (R1), assumindo como ativos financeiros os investimentos do negócio. Conforme demonstrado no Quadro 3, os contratos de concessão são aderentes ao modelo ativo financeiro. 
ANÁLISE DOS EFEITOS DA ICPC 01 (R1) - CONTRATOS DE CONCESSÃO NAS DECISÕES GERENCIAIS NAS EMPRESAS DE TRANSMISSÃO DE ENERGIA ELÉTRICA

\begin{tabular}{ll}
\hline \multirow{2}{*}{ Análise } & $\begin{array}{l}\text { De acordo com os } \\
\text { Contratos de Concessão } \\
\text { Analisados }\end{array}$ \\
\cline { 2 - 2 } \begin{tabular}{l} 
Transmissão \\
\hline A Concedente controla ou regula quais serviços o Operador deve prestar?
\end{tabular} & Sim \\
\hline A Concedente controla o preço e define o cliente do Operador? & Sim \\
\hline $\begin{array}{l}\text { A Concedente controla qualquer participação residual na infraestrutura ao } \\
\text { final da concessão? }\end{array}$ & Sim \\
\hline $\begin{array}{l}\text { O Operador tem direito contratual a receber caixa, ou outro ativo } \\
\text { financeiro, da Concedente ou conforme sua instrução? }\end{array}$ & Sim \\
\hline $\begin{array}{l}\text { O Operador tem direito contratual de cobrar os usuários dos serviços } \\
\text { públicos de concessão de energia? }\end{array}$ & Sim \\
\hline $\begin{array}{l}\text { De acordo com ICPC 01-Contratos de Concessão, nestes casos, deve ser } \\
\text { reconhecido nos demonstrativos financeiros }\end{array}$ & Ativo Financeiro \\
\hline
\end{tabular}

QuAdro 3 - Análise do Contrato de Concessão de Transmissoras do Grupo Alupar Investimento S/A Fonte: Adaptado de Gouveia (2010).

\section{ANÁLISE DA PESQUISA QUALITATIVA}

Buscou-se evidenciar o entendimento dos gestores acerca da ICPC 01 (R1) e qual o impacto desta em seus processos decisórios.

Os cinco respondentes afirmaram que as decisões gerenciais são tomadas com base nas informações contábeis regulatórias e por isso são as informações mais solicitadas pelos gestores. De acordo com as respostas, praticamente nenhuma decisão é tomada a partir das informações contábeis societárias. Todos os respondentes concor- daram que a ICPC 01 (R1) trouxe mudanças relevantes para o negócio de transmissão de energia; no entanto, tais mudanças não modificaram a fonte das informações para decisões gerenciais e que a publicação das Demonstrações Regulatórias é importante porque é a informação base para decisão e trouxe mais transparência para o investidor. Todos concordaram ser a adoção da ICPC 01 (R1) uma mera exigência da legislação societária, e o fator que mais impactou o negócio foi a adequação da receita no período de concessão. 


\section{CONCLUSÃO E CONTRIBUIÇÃO}

Este relato evidenciou que as informações utilizadas para tomada de decisões internas pelos gestores das empresas transmissoras de energia elétricas provêm das normas regulatórias e que, praticamente, nenhuma decisão gerencial é tomada a partir das normas societárias.

Concluiu-se, assim, que a ICPC 01 (R1) - Contratos de Concessão não trouxe alterações na fonte de informações para a tomada de decisão pelos gestores das empresas de transmissão de energia elétrica do Brasil.

Este relato contribui no sentido de destacar que as informações contábeis decorrentes da ICPC 01 (R1) não contribuem para o processo de gestão e tomada de decisão gerencial para as empresas da amostra.

A principal limitação deste relato é que foi realizado junto às empresas de transmissão de energia do Grupo Alupar, não tendo sido abordadas a geração, a distribuição e a comercialização de energia. Portanto, os resultados obtidos se limitaram ao negócio de transmissão.

\section{ANALYSIS OF THE EFFECTS OF ICPC 01 (R1) - SERVICE CONCESSION ARRANGEMENTS, IN MANAGEMENT DECISIONS IN ELECTRIC POWER TRANSMISSION COMPANIES}

\section{ABSTRACT}

This technical report is based on the adoption by the electric power transmission companies of ICPC 01 (R1) - Concession Contracts, which brought significant changes in the accounting records related to revenue and business infrastructure for the sector, more specifically the transmission of energy. The purpose of this report was to analyze if there was a change in the source of information used as a basis for management decision making by managers of electric energy transmission companies after the adoption of ICPC 01 (R1). This is an exploratory study, with a qualitative approach, carried out with five managers from the holding company of the Alupar Investimento S.A. Group, using a questionnaire with 12 open questions. The results showed that the information used for internal decision-making comes from the regulatory norms and that, practically, no managerial decision is taken from the corporate norms. It was concluded, therefore, that ICPC 01 (R1) did not bring changes in the source of information for the decision-making by the managers of the transmission companies of electric energy of Brazil. This report contributes to 
highlight that the accounting information resulting from ICPC 01 (R1) does not contribute to the management process and management decision making for the sample companies.

\section{KEYWORDS}

Regulatory statements. Corporate statements. Managerial decisions. Transmission of electrical energy.

\section{REFERÊNCIAS}

ABREU, Y. V. Reestruturação e privatização do setor elétrico brasileiro. Edición electrónica gratuita, 2009. Disponível em: $<$ www.eumed.net/libros/2009a/486/ $\geq$. Acesso em: 13 set. 2013.

AGÊNCIA NACIONAL DE ENERGIA ELÉTRICA (ANEEL). Disponível em: <www. aneel.gov.br>. Acesso em: jun. 2012.

AGÊNCIA NACIONAL DE ENERGIA ELÉTRICA (ANEEL). Resolução Homologatória Aneel 1.313, de 26 de junho de 2012. Estabelece as receitas anuais permitidas - RAPs pela disponibilização das instalações sob responsabilidade de concessionárias de serviços públicos de transmissão de energia e dá outras providências. Disponível em: <https://www.jusbrasil.com.br/diarios/ 38321671/dou-secao-1-29-06-2012pg-73>. Acesso em: 15 set. 2012.
ALUPAR INVESTIMENTO S.A. Estrutura Societária. Disponível em: <http://ri.alupar.com.br/a-companhia/estrutura-societaria/>. Acesso em: 15 set. 2012.

ALUPAR INVESTIMENTO S.A. Empresas. Disponível em: <http://www.alupar.com. br/empresas/>. Acesso em: 15 set. 2012.

BEUREN, I. M. Como elaborar trabalhos monográficos em contabilidade: teoria e prática. 2. ed. São Paulo: Atlas, 2008.

COMITÊ DE PRONUNCIAMENTOS CONTÁBEIS (CPC). A Busca da Convergência da Contabilidade aos Padrões Internacionais. Disponível em: <http://cpc.org.br/ pdf/CPC-plano\%20de\%20converg\%C3\%AAncia\%20_\%20novembro\%20 de\%202008_proposta.pdf>. Acesso em: 12 maio 2012.

COMITÊ DE PRONUNCIAMENTOS CONTÁBEIS (CPC). Interpretação ICPC 01 Contratos de Concessão. Disponível em: $<$ http://www.cpc.org.br/CPC/Documentos-Emitidos/Interpretacoes/Interpretacao?Id=10>. Acesso em: 12 maio 2012.

COMITÊ DE PRONUNCIAMENTOS CONTÁBEIS (CPC). Orientação OCPC 05 Contratos de Concessão. Disponível em: $<$ http://www.cpc.org.br/CPC/DocumentosEmitidos/Orientacoes/Orientacao?Id=32>. Acesso em: 13 maio 2012. 
EMPRESA DE TRANSMISSÃO DE ENERGIA DO MATO GROSSO S/A - ETEM. Disponível em: <www.etemsa.com.br>. Acesso em: 15 set. 2012.

EMPRESA DE TRANSMISSÃO DO ESPÍRITO SANTO S/A - ETES. Disponível em: <www.etesenergia.com.br>. Acesso em: 15 set. 2012 .

FERREIRA, C. M. A. O equilíbrio econômico-financeiro das distribuidoras de energia elétrica brasileiras nas demonstrações contábeis. 2009. Dissertação (Mestrado em Contabilidade) - Faculdade de Economia, Administração e Contabilidade de Ribeirão Preto, Universidade de São Paulo, Ribeirão Preto, 2009.

GOUVEIA, A. L. G. Estudo sobre o impacto da ICPC 01 - Contrato de concessão sobre os indicadores de desempenho econômico-financeiro das empresas do setor elétrico. 2010. Dissertação (Mestrado) - Universidade Presbiteriana Mackenzie, São Paulo, 2010.

IUDÍCIBUS, S.; MARTINS, E.; GELBCKE, E. R.; SANTOS, A. Manual de contabilidade societária: aplicável a todas as sociedades. São Paulo: Atlas, 2010.
OPERADOR NACIONAL DO SISTEMA ELÉTRICO - ONS. Disponível em: <http:// www.ons.org.br/institucional/agentes_ transmissao.aspx>. Acesso em: 14 set. 2012.

SISTEMA DE TRANSMISSÃO NORDESTE S/A - STN. Disponível em: <www.stnordeste.com.br>. Acesso em: 15 set. 2012.

TRANSMISSÃO MINEIRA - TRANSMINEIRA. Disponível em: <www.transmineira.com.br>. Acesso em: 15 set. 2012.

TRANSMISSORA MATOGROSSENSE DE ENERGIA S/A - TME. Disponível em: <www.tmesa.com.br>. Acesso em: 15 set. 2012.

TRANSMISSORAS BRASILEIRAS DE ENERGIA - TBE. Disponível em: <www. tbe.com.br>. Acesso em: 15 set. 2012. 